\title{
Stochastic sensitivity in metal forming of rigid-poroplastic materials
}

\author{
Andrzej Sluzalec
}

Received: 27 October 2010 / Revised: 14 April 2011 / Accepted: 5 May 2011 / Published online: 7 July 2011

(C) The Author(s) 2011. This article is published with open access at Springerlink.com

\begin{abstract}
Stochastic sensitivity in metal forming process of rigid-poroplastic material is analyzed. The theoretical formulation for stochastic sensitivity is described which presents probabilistic distributions taking into account random initial and boundary conditions. The stochastic equations for metal forming process as well as for stochastic sensitivities are presented. Stochastic finite element equations for rigid-poroplastic materials are solved for the first two probabilistic moments. As the examples the sensitivity problems in the process of compression of rigid-poroplastic ring with random material parameters are discussed. The differences in deterministic and stochastic sensitivities are presented. The results derived can be used for the subsequent quantitative stochastic design as well as stochastic optimization.
\end{abstract}

Keywords Stochastic sensitivity .

Parameter sensitivity $\cdot$ Metal forming .

Finite element method · Rigid-poroplasticity

\section{Introduction}

The sensitivity in deterministic analysis is widely used to solve the problems of optimization and design of engineering structures and this subject was undertaken in many publications. Recently stochastic optimization methods have become an area of interest in metal forming. These methods combine two methodologies developed to deal with problems of metal forming: analytical or numerical analysis in

\footnotetext{
A. Sluzalec ( $\bowtie)$

Technical University of Czestochowa,

42-200 Czestochowa, ul. Dąbrowskiego 69, Poland

e-mail: sluzalec@k2.pcz.pl
}

optimization problem with the stochastic one. In the paper the stochastic sensitivity is discussed in the process of metal forming of rigid-poroplastic material.

Modern metallurgical technology requires materials with improved characteristics as wear and corrosion resistance as well as specific strength properties. In this context powder metallurgy has much to offer because powder metallurgical processing produces materials of extremely fine and uniform microstructure and enables the formulation of materials composed from different constituents yielding unique property combinations. We can change and optimize material properties of powder materials by mixing the different powders of quite different properties, and then obtain the materials of specific properties; in particular we can modify the strain-stress curve (see Kuhn 1978; Pokorska 2008a, b for instance).

The rigid-poroplastic analysis is widely used in powder forging modeling. The models of poroplastic materials are presented for instance in works Pokorska $(2007,2008 \mathrm{a}$, b, c, d).

The stochastic analysis in optimization and design problems refers to the explicit treatment of uncertainty in any quantity entering the corresponding deterministic analysis. The exact values of quantities which are inputs in optimization problems are not precisely known because they cannot be precisely measured.

Existing uncertain variations in parameters may have significant effects on such fundamental final characteristics, such as density distributions, and they must affect the final design and optimization.

The necessity of performing numerical calculations while analyzing the stochastic behavior of manufacturing processes has now been widely recognized. Since uncertainties appear in the operators of governing equations, systems of equations are functions of random variables. The distin- 
guishing feature of the stochastic methods, which is based on the perturbation approach, is treating probabilistic problems with deterministic computational techniques that take full advantage of the mathematical properties of linear and nonlinear operators.

The subject of the design sensitivity analysis in the specific context of nonlinear elasto-plastic and rigid-plastic problems was undertaken in many publications (see Haug and Arora 1979; Haug et al. 1986; Kuhn 1978; Repalle et al. 2007 for instance). Sensitivity for rigid-poroplastic material model has been discussed in Pokorska (2007, 2008a, c). The stochastic elements are described for instance in the works Liu et al. (1986a, b). The stochastic metal forming process was discussed for instance in the author's publications (Grzywinski and Sluzalec 2002; Sluzalec 2000, 2004). However the stochastic sensitivity in rigid-poroplasticity and in metal forming processes is not undertaken in literature. The approach presented is based on Kleiber et al. (1995) but it describes the different material model. The paper recalls known equations of deterministic sensitivity and then consider stochastic sensitivity equations based on perturbation methods.

\section{The rigid-poroplastic finite element model}

The loading functions for porous material are discussed by many authors (Kuhn 1978; Pokorska 2007, 2008b). For isotropic models of plasticity this function can be expressed as

$\mathrm{F}=\mathrm{F}(\mathrm{h}, \mathrm{p})$

where $\mathrm{h}^{2}=\mathrm{J}_{2 s}(\boldsymbol{\sigma})=\frac{1}{2} \mathrm{~s}_{\mathrm{ij}} \mathrm{s}_{\mathrm{ji}}=\frac{1}{2} \operatorname{tr}(\mathbf{s} \cdot \mathbf{s}), 3 \mathrm{p}=\operatorname{tr} \boldsymbol{\sigma}=$ $\mathrm{J}_{1 \sigma}(\sigma), \sigma$ is the stress tensor, $\mathrm{J}_{1 \sigma}$ is the first invariant of the stress tensor and $\mathrm{J}_{2 \mathrm{~s}}$ is the second invariant of the stress deviator tensor $\mathbf{s}=\boldsymbol{\sigma}-(\operatorname{tr} \boldsymbol{\sigma} / 3) \mathbf{1}$.

In the paper the loading function for porous material is assumed in the form

$\mathrm{f}=\mathrm{AJ}_{2}^{\prime}+\frac{(3-\mathrm{A})}{3} \mathrm{~J}_{1}^{2}-\mathrm{Y}_{\tilde{\rho}}^{2}=0$

where $\mathrm{A}$ is the material parameter and $\mathrm{Y}_{\tilde{\rho}}$ is the apparent yield stress of the porous material in uniaxial tension

The apparent yield stress of porous materials, $\mathrm{Y}_{\tilde{\rho}}$ can be written as follows

$Y_{\tilde{\rho}}^{2}=\mu(\tilde{\rho}) Y_{b}^{2}$

where $\mu$ is a function of relative density $\tilde{\rho}$ and $Y_{b}$ is the yield stress of base material.

The stress-strain relation for rigid-poroplastic material is

$\dot{\epsilon}_{\mathrm{ij}}=\dot{\lambda}\left[\mathrm{A} \sigma_{\mathrm{ij}}+3(2-\mathrm{A}) \sigma_{\mathrm{m}} \delta_{\mathrm{ij}}\right]$ where $\sigma_{\mathrm{m}}=-\mathrm{p}=\frac{1}{3} \sigma_{\mathrm{ij}}$ is the hydrostatic component of stress, and

$\delta_{i j}= \begin{cases}0 & (i \neq j) \\ 1 & (i=i)\end{cases}$

is the Kronecker delta.

The proportionality factor $\dot{\lambda}$ is equal to

$\dot{\lambda}=\frac{\dot{\bar{\epsilon}}_{\tilde{\rho}}}{2 \mathrm{Y}_{\tilde{\rho}}}$

where $\dot{\bar{\epsilon}}_{\tilde{\rho}}$ is the apparent effective strain-rate and is defined according to $\sigma_{\mathrm{ij}} \dot{\varepsilon}_{\mathrm{ij}}=\mathrm{Y}_{\tilde{\rho}} \dot{\bar{\varepsilon}}_{\tilde{\rho}}$

It can be expressed by

$$
\begin{array}{r}
\dot{\bar{\epsilon}}_{\tilde{\rho}}^{2}=\frac{1}{\mathrm{~A}}\left[\frac { 2 } { 3 } \left\{\left(\dot{\epsilon}_{\mathrm{x}}-\dot{\epsilon}_{\mathrm{y}}\right)^{2}+\left(\dot{\epsilon}_{\mathrm{y}}-\dot{\epsilon}_{\mathrm{z}}\right)^{2}+\left(\dot{\epsilon}_{\mathrm{z}}-\dot{\epsilon}_{\mathrm{x}}\right)^{2}\right.\right. \\
\left.\left.+4\left(\dot{\epsilon}_{\mathrm{xy}}^{2}+\dot{\epsilon}_{\mathrm{yz}}^{2}+\dot{\epsilon}_{\mathrm{zx}}^{2}\right)\right\}\right]+\frac{\epsilon_{\mathrm{v}}^{2}}{3(3-\mathrm{A})}
\end{array}
$$

where $\dot{\epsilon}_{\mathrm{v}}$ is the volumetric strain-rate.

By (2), (3) and the virtual work theorem we get the finite element matrix equation

$\mathbf{K} \mathbf{u}=\mathbf{Q}$

where

$\mathbf{Q}=\int_{\mathrm{u}} \mathbf{N} \mathbf{t d}(\partial \Omega)$

$\mathbf{K}=\int_{\Omega} \dot{\lambda} \mathbf{B}^{T} \mathbf{D} \mathbf{B} \mathrm{d} \Omega$

and

$\mathbf{D}=\left[\begin{array}{cccccc}\frac{4-\mathrm{A}}{\mathrm{A}(3-\mathrm{A})} & \frac{\mathrm{A}-2}{\mathrm{~A}(3-\mathrm{A})} & \frac{\mathrm{A}-2}{\mathrm{~A}(3-\mathrm{A})} & 0 & 0 & 0 \\ \frac{\mathrm{A}-2}{\mathrm{~A}(3-\mathrm{A})} & \frac{4-\mathrm{A}}{\mathrm{A}(3-\mathrm{A})} & \frac{\mathrm{A}-2}{\mathrm{~A}(3-\mathrm{A})} & 0 & 0 & 0 \\ \frac{\mathrm{A}-2}{\mathrm{~A}(3-\mathrm{A})} & \frac{\mathrm{A}-2}{\mathrm{~A}(3-\mathrm{A})} & \frac{4-\mathrm{A}}{\mathrm{A}(3-\mathrm{A})} & 0 & 0 & 0 \\ 0 & 0 & 0 & \frac{1}{\mathrm{~A}} & 0 & 0 \\ 0 & 0 & 0 & 0 & \frac{1}{\mathrm{~A}} & 0 \\ 0 & 0 & 0 & 0 & 0 & \frac{1}{\mathrm{~A}}\end{array}\right]$

where $\mathbf{u}$ is the displacement rate vector, $\mathbf{t}$ are surface tractions, $\mathbf{N}$ are shape functions for finite elements and $\mathbf{B}$ is the strain-displacement rate matrix. 


\section{Sensitivity in rigid-poroplasticity}

Consider matrix equation for rigid-poroplasticity in the form of (7) where the so-called design parameter $\mathbf{h}$ is introduced

$\mathbf{K}(\mathbf{h}) \mathbf{u}(\mathbf{h})=\mathbf{Q}(\mathbf{h})$

The above equation can be solved by step-by-step method (Bathe 1995). The (11) is linearized in time step $\Delta t$ (see Bathe 1995 for instance) by iterative procedure with respect to $\Delta \mathrm{t}$ to minimize $\frac{\partial \mathbf{K}}{\partial \mathrm{u}} \Delta \mathrm{u}$ (i.e. $\frac{\partial \mathbf{K}}{\partial \mathrm{u}} \Delta \mathrm{u} \rightarrow 0$ ).

Then differentiating (11) in any small time step with respect to $\mathbf{h}$ gives

$\mathbf{K} \frac{\mathrm{d} \mathbf{u}}{\mathrm{dh}}=\frac{\mathrm{d} \mathbf{Q}}{\mathrm{d} \mathbf{h}}-\frac{\mathrm{d} \mathbf{K}}{\mathrm{dh}} \mathbf{u}$

The expression (12) is used to calculate the derivatives $\frac{\mathrm{du}}{\mathrm{dh}}$. The method shown above is known as the direct differentiation method.

\section{Stochastic metal forming process}

Consider the finite element (7) in which the matrix $\mathbf{K}$ and the vectors $\mathbf{Q}$ and $\mathbf{u}$ are functions of random variable $\mathbf{b}$

$\mathbf{K}(\mathbf{b}) \mathbf{u}(\mathbf{b})=\mathbf{Q}(\mathbf{b})$

All the random functions are expanded about the mean value $\mathrm{E}(\mathbf{b})$ via a Taylor series and only up to second order terms are retained. For any small parameter $\delta$ we have

$$
\begin{aligned}
\mathbf{u}(\mathbf{b}, \mathrm{t})= & E(\mathbf{u}(\mathrm{t}))+\delta \sum_{\mathrm{i}=1}^{\mathrm{q}} \mathrm{E}\left(\mathbf{u}_{\mathrm{b}_{\mathrm{i}}}(\mathrm{t}) \Delta \mathrm{b}_{\mathrm{i}}\right) \\
& +\frac{1}{2} \delta^{2} \sum_{\mathrm{i}, \mathrm{j}=1}^{\mathrm{q}} \mathrm{E}\left(\mathbf{u}_{\mathrm{b}_{\mathrm{i}} \mathrm{b}_{\mathrm{j}}}(\mathrm{t})\right) \Delta \mathrm{b}_{\mathrm{i}} \Delta \mathrm{b}_{\mathrm{j}}
\end{aligned}
$$

where $\mathrm{t}$ is the time variable, $\Delta \mathrm{b}_{\mathrm{i}}$ represents the first-order variation of $\mathrm{b}_{\mathrm{i}}$ about $\mathrm{E}\left(\mathrm{b}_{\mathrm{i}}\right)$ where $\mathrm{b}_{i}$ are the nodal values of $b(\mathbf{x})$, that is the values of $b$ at $x_{i}, i=1, \ldots, R$. For a linearized equation in each time step for any function $\mathrm{g}$ the following notations are used $\mathrm{E}(\mathrm{g}(\mathrm{x}))=\mathrm{g}(\mathrm{x}, \mathrm{E}(\mathrm{b})), \mathrm{g}_{\mathrm{bi}}=$ $\frac{\partial \mathrm{g}}{\partial \mathrm{b}_{\mathrm{i}}}, \mathrm{g}_{\mathrm{b}_{\mathrm{i}} \mathrm{b}_{\mathrm{j}}}=\frac{\partial^{2} \mathrm{~g}}{\partial \mathrm{b}_{\mathrm{i}} \partial \mathrm{b}_{\mathrm{j}}}$. In a similar way as it is in (14) we can express $\mathbf{K}(\mathbf{b})$ and $\mathbf{Q}(\mathbf{b})$

$$
\begin{aligned}
\mathbf{K}(\mathbf{b})= & \mathrm{E}(\mathbf{K})+\delta \sum_{\mathrm{i}=1}^{\mathrm{q}} \mathrm{E}\left(\mathbf{K}_{\mathrm{b}_{\mathrm{i}}}\right) \Delta \mathrm{b}_{\mathrm{i}} \\
& +\frac{1}{2} \delta^{2} \sum_{\mathrm{i}, \mathrm{j}=1}^{2} \mathrm{E}\left(\mathbf{K}_{\mathrm{b}_{\mathrm{i}} \mathrm{b}_{\mathrm{j}}}\right) \Delta \mathrm{b}_{\mathrm{i}} \Delta \mathrm{b}_{\mathrm{j}}
\end{aligned}
$$

$$
\begin{aligned}
\mathbf{Q}(\mathbf{b})= & \mathrm{E}(\mathbf{Q})+\delta \sum_{\mathrm{i}=1}^{\mathrm{q}} \mathrm{E}\left(\mathbf{Q}_{\mathrm{b}_{\mathrm{i}}}\right) \Delta \mathrm{b}_{\mathrm{i}} \\
& +\frac{1}{2} \delta^{2} \sum_{\mathrm{i}, \mathrm{j}=1}^{2} \mathrm{E}\left(\mathbf{Q}_{\mathrm{b}_{\mathrm{i}} \mathrm{b}_{\mathrm{j}}}\right) \Delta \mathrm{b}_{\mathrm{i}} \mathrm{b}_{\mathrm{j}}
\end{aligned}
$$

Substitution of (14), (15) and (16) into (13) and collecting terms of order $\delta^{0}, \delta^{1}$ and $\delta^{2}$ the following equations for $\mathrm{E}(\mathbf{u}), \mathrm{E}\left(\mathbf{u}_{\mathrm{b}_{\mathrm{i}}}\right)$, and $\mathrm{E}\left(\mathbf{u}_{\mathrm{b}_{\mathrm{i}} \mathrm{b}_{\mathrm{j}}}\right)$ are derived:

Zero order $\left(\delta^{0}\right.$ terms $)$

$\mathrm{E}(\mathbf{K}) \mathrm{E}(\mathbf{u})=\mathrm{E}(\mathbf{Q})$

First order ( $\delta^{1}$ terms $)$

$\mathrm{E}(\mathbf{K}) \mathrm{E}\left(\mathbf{u}_{\mathrm{b}_{\mathrm{i}}}\right)=\mathrm{E}\left(\mathbf{Q}_{\mathrm{b}_{\mathrm{i}}}\right)$

where

$\mathrm{E}\left(\mathbf{Q}_{\mathrm{b}_{\mathrm{i}}}\right)=\mathrm{E}\left(\mathbf{Q}_{\mathrm{b}_{\mathrm{i}}}\right)-\left(\mathrm{E}\left(\mathbf{K}_{\mathrm{b}_{\mathrm{i}}}\right) \mathrm{E}(\mathbf{u})\right)$

Second order ( $\delta^{2}$ terms $)$

$\mathrm{E}(\mathbf{K}) \hat{\mathbf{u}}_{2}=\hat{\mathbf{Q}}_{2}$

where

$$
\begin{aligned}
\hat{\mathbf{Q}}_{2}=\sum_{\mathrm{i}, \mathrm{j}=1}^{\mathrm{q}}\{[ & \left.\left.\frac{1}{2} \mathrm{E}\left(\mathbf{Q}_{\mathrm{b}_{\mathrm{i}} \mathrm{b}_{\mathrm{j}}}\right) \operatorname{Cov}\left(\mathrm{b}_{\mathrm{i}}, \mathrm{b}_{\mathrm{j}}\right)\right]\right\} \\
-\sum_{\mathrm{i}, \mathrm{j}=1}^{\mathrm{q}}\{ & \left\{\left[\frac{1}{2} \mathrm{E}\left(\mathbf{K}_{\mathrm{b}_{\mathrm{i}} \mathrm{b}_{\mathrm{j}}}\right) \mathrm{E}(\mathbf{u})+\mathrm{E}\left(\mathbf{K}_{\mathrm{b}_{\mathrm{i}}}\right) \mathrm{E}\left(\mathbf{u}_{\mathrm{b}_{\mathrm{i}}}\right)\right]\right. \\
& \left.\times \operatorname{Cov}\left(\mathrm{b}_{\mathrm{i}}, \mathrm{b}_{\mathrm{j}}\right)\right\}
\end{aligned}
$$

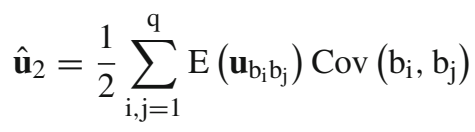

$\operatorname{Cov}\left(b_{i} b_{j}\right)=\left[\operatorname{Var}\left(b\left(\mathbf{x}_{i}\right)\right), \operatorname{Var}\left(b\left(\mathbf{x}_{j}\right)\right)\right]^{\frac{1}{2}}$

$$
\times \mathrm{R}\left(\mathrm{b}\left(\mathbf{x}_{\mathrm{i}}\right), \mathrm{b}\left(\mathbf{x}_{\mathrm{j}}\right)\right)
$$

and $\mathrm{R}\left(\mathrm{b}\left(\mathbf{x}_{\mathrm{i}}\right), \mathrm{b}\left(\mathbf{x}_{\mathrm{j}}\right)\right)$ is the autocorrelation. The definition for the expectation and cross-covariance of the displacement rate vector $\mathbf{u}$ are given by

$E(\mathbf{u})=\int_{-\infty}^{+\infty} \mathbf{u}(\mathbf{b}) \mathrm{p}(\mathbf{b}) \mathrm{d} \mathbf{b}$ 
and

$$
\begin{aligned}
& \operatorname{Cov}\left(\mathbf{u}^{\mathrm{i}}, \mathbf{u}^{\mathrm{j}}\right) \\
& =\int_{-\infty}^{+\infty}\left(\mathbf{u}^{\mathrm{i}}-\mathrm{E}\left(\mathbf{u}^{\mathrm{i}}\right)\left(\mathbf{u}^{\mathrm{j}}-\mathrm{E}\left(\mathbf{u}^{\mathrm{j}}\right)\right)\right) p(\mathbf{b}) \mathrm{d} \mathbf{b}
\end{aligned}
$$

where $p(\mathbf{b})$ is the joint probability density function. The second-order estimate of the mean value of $\mathbf{u}$ is obtained from (14) to give

$E(\mathbf{u})=\mathbf{u}(E(\mathbf{b}))+\frac{1}{2}\left\{\sum_{i, j=1}^{q} E\left(\mathbf{u}_{b_{i} b_{j}}\right) \operatorname{Cov}\left(b_{i}, b_{j}\right)\right\}$

\section{Stochastic sensitivity in rigid-poroplasticity}

Consider sensitivity equation in the form of (12) in which the matrix $\mathbf{K}$ and the vectors $\mathbf{Q}$ and $\mathbf{u}$ are functions of the random variable $\mathbf{b}$

$\mathbf{K} \frac{\partial \mathbf{u}(\mathbf{b})}{\partial \mathbf{h}}=\frac{\mathrm{d} \mathbf{Q}(\mathbf{b})}{\mathrm{d} \mathbf{h}}-\frac{\mathrm{d} \mathbf{K}}{\partial \mathbf{h}} \mathbf{u}$

Next the random functions are expanded about the mean value $\mathrm{E}(\mathbf{b})$ via a Taylor series only up to second order. We get for any small parameter $\delta$

$$
\begin{aligned}
& \mathbf{u}(\mathbf{b}, \mathrm{t})=\mathrm{E}(\mathbf{u}(\mathrm{t}))+\delta \sum_{\mathrm{i}=1}^{\mathrm{q}} \mathrm{E}\left(\mathbf{u}_{\mathrm{b}_{\mathrm{i}}}(\mathrm{t}) \Delta \mathrm{b}_{\mathrm{i}}\right) \\
& +\frac{1}{2} \delta^{2} \sum_{\mathrm{i}, \mathrm{j}=1}^{\mathrm{q}} \mathrm{E}\left(\mathbf{u}_{\mathrm{b}_{\mathrm{i}} \mathrm{b}_{\mathrm{j}}}(\mathrm{t})\right) \Delta \mathrm{b}_{\mathrm{i}} \Delta \mathrm{b}_{\mathrm{j}} \\
& \frac{\partial \mathbf{u}}{\partial \mathbf{h}}(\mathrm{b}, \mathrm{t})=\mathrm{E}\left(\frac{\partial \mathbf{u}}{\partial \mathbf{h}}(\mathrm{t})\right)+\delta \sum_{\mathrm{i}=1}^{\mathrm{q}} \mathrm{E}\left(\frac{\partial \mathbf{u}}{\partial \mathbf{h}} \mathrm{b}_{\mathrm{i}}(\mathrm{t})\right) \Delta \mathrm{b}_{\mathrm{i}} \\
& +\frac{1}{2} \delta^{2} \sum_{i=1}^{\mathrm{q}} \mathrm{E}\left(\frac{\partial \mathbf{u}}{\partial \mathbf{h}} \mathrm{b}_{\mathrm{i}} \mathrm{b}_{\mathrm{j}}(\mathrm{t}) \Delta \mathrm{b}_{\mathrm{i}}\right) \Delta \mathrm{b}_{\mathrm{i}} \Delta \mathrm{b}_{\mathrm{j}}
\end{aligned}
$$

In a similar way we can express $\mathbf{K}(\mathbf{b}), \mathbf{Q}(\mathbf{b}), \frac{\partial \mathbf{K}(\mathbf{b})}{\partial \mathbf{h}}$ and $\frac{\partial \mathbf{Q}(\mathbf{b})}{\partial \mathbf{h}}$

$$
\begin{aligned}
\mathbf{K}(\mathbf{b})= & \mathrm{E}(\mathbf{K})+\delta \sum_{\mathrm{i}=1}^{\mathrm{q}} \mathrm{E}\left(\mathbf{K}_{\mathrm{b}_{\mathrm{i}}}\right) \Delta \mathrm{b}_{\mathrm{i}} \\
& +\frac{1}{2} \delta^{2} \sum_{\mathrm{i}, \mathrm{j}=1}^{2} \mathrm{E}\left(\mathbf{K}_{\mathrm{b}_{\mathrm{i}} \mathrm{b}_{\mathrm{j}}}\right) \Delta \mathrm{b}_{\mathrm{i}} \Delta \mathrm{b}_{\mathrm{j}}
\end{aligned}
$$

$$
\begin{aligned}
\frac{\partial \mathbf{K}}{\partial \mathbf{h}}(\mathbf{b})= & \mathrm{E}\left(\frac{\partial \mathbf{K}}{\partial \mathbf{h}}\right)+\delta \sum_{\mathrm{i}=1}^{\mathrm{q}} \mathrm{E}\left(\frac{\partial \mathbf{K}_{\mathrm{b}_{\mathrm{i}}}}{\partial \mathbf{h}}\right) \\
& +\frac{1}{2} \delta^{2} \sum_{\mathrm{i}, \mathrm{j}=1}^{\mathrm{q}} \mathrm{E}\left(\frac{\partial \mathbf{K}_{\mathrm{b}_{\mathrm{i}}} \mathrm{b}_{\mathrm{j}}}{\partial \mathbf{h}}\right) \Delta \mathrm{b}_{\mathrm{i}} \Delta \mathrm{b}_{\mathrm{j}}
\end{aligned}
$$

$$
\begin{aligned}
& \mathbf{Q}(\mathbf{b})= \mathrm{E}(\mathbf{Q})+\delta \sum_{\mathrm{i}=1}^{\mathrm{q}} \mathrm{E}\left(\mathbf{Q}_{\mathrm{b}_{\mathrm{i}}}\right) \Delta \mathrm{b}_{\mathrm{i}} \\
&+ \frac{1}{2} \delta^{2} \sum_{\mathrm{i}, \mathrm{j}=1}^{2} \mathrm{E}\left(\mathbf{Q}_{\mathrm{b}_{\mathrm{i}} \mathrm{b}_{\mathrm{j}}}\right) \Delta \mathrm{b}_{\mathrm{i}} \mathrm{b}_{\mathrm{j}} \\
& \frac{\partial \mathbf{Q}}{\partial \mathbf{h}}(\mathbf{b})=\mathrm{E}\left(\frac{\partial \mathbf{Q}}{\partial \mathbf{h}}\right)+\delta \sum_{\mathrm{i}=1}^{\mathrm{q}} \mathrm{E}\left(\frac{\partial \mathbf{Q}_{\mathrm{b}_{\mathrm{i}}}}{\partial \mathbf{h}}\right) \Delta \mathrm{b}_{\mathrm{i}} \\
&+\frac{1}{2} \delta^{2} \sum_{\mathrm{i}, \mathrm{j}=1}^{\mathrm{q}} \mathrm{E}\left(\frac{\partial \mathbf{Q}_{\mathrm{b}_{\mathrm{i}} \mathrm{b}_{\mathrm{j}}}}{\partial \mathbf{h}}\right) \Delta \mathrm{b}_{\mathrm{i}} \Delta \mathrm{b}_{\mathrm{j}}
\end{aligned}
$$

Substitution of (27)-(32) into (26) and collecting terms of order $\delta^{0}, \delta^{1}$ and $\delta^{2}$ the following equations for $\mathrm{E}\left(\frac{\partial \mathbf{u}}{\partial \mathbf{h}}\right)$, $\mathrm{E}\left(\frac{\partial \mathbf{u}_{\mathrm{b}_{\mathrm{i}}}}{\partial \mathbf{h}}\right)$, and $\mathrm{E}\left(\frac{\partial \mathbf{u}_{\mathrm{b}_{\mathrm{i}} \mathrm{b}_{\mathrm{j}}}}{\partial \mathbf{h}}\right)$ are derived:

Zero order $\left(\delta^{0}\right.$ terms $)$

$\mathrm{E}(\mathbf{K}) \mathrm{E}\left(\frac{\partial \mathbf{u}(\mathbf{b})}{\partial \mathbf{h}}\right)=\mathrm{E}\left(\frac{\mathrm{d} \mathbf{Q}(\mathbf{b})}{\mathrm{dh}}\right)-\mathrm{E}\left(\frac{\mathrm{d} \mathbf{K}}{\mathrm{dh}}\right) \mathrm{E}(\mathbf{u})$

First order $\left(\delta^{1}\right.$ terms $)$

$\mathrm{E}(\mathbf{K}) \mathrm{E}\left(\frac{\partial \mathbf{u}_{\mathrm{b}_{\mathrm{i}}}}{\partial \mathbf{h}}\right)=\mathrm{E}\left(\mathbf{Q}_{\mathrm{b}_{\mathrm{i}}}\right)$

where

$$
\begin{aligned}
\mathrm{E}\left(\mathbf{Q}_{1 \mathbf{b}_{\mathrm{i}}}\right)= & \mathrm{E}\left(\frac{\mathrm{d} \mathbf{Q}_{\mathrm{b}_{\mathrm{i}}}}{\mathrm{dh}}\right)-\left(\mathrm{E}\left(\frac{\partial \mathbf{K}_{\mathrm{b}_{\mathrm{i}}}}{\partial \mathbf{h}}\right) \mathrm{E}(\mathbf{u})\right) \\
& -\mathrm{E}\left(\frac{\partial \mathbf{K}}{\partial \mathbf{h}}\right) \mathrm{E}\left(\mathbf{u}_{\mathrm{b}_{\mathrm{i}}}\right)
\end{aligned}
$$

Second order ( $\delta^{2}$ terms $)$

$\mathrm{E}(\mathbf{K}) \hat{\mathbf{u}}_{2}=\hat{\mathbf{Q}}_{2}$

where

$$
\begin{aligned}
\hat{\mathbf{Q}}_{2}=\sum_{\mathrm{i}, \mathrm{j}=1}^{\mathrm{q}}\left\{\left[\frac{1}{2} \mathrm{E}\left(\frac{\partial \mathbf{Q}_{\mathrm{b}_{\mathrm{i}} \mathrm{b}_{\mathrm{j}}}}{\mathbf{h}}\right) \operatorname{Cov}\left(\mathrm{b}_{\mathrm{i}}, \mathrm{b}_{\mathrm{j}}\right)\right]\right\} \\
-\sum_{\mathrm{i}, \mathrm{j}=1}^{\mathrm{q}}\left\{\left[\frac{1}{2} \mathrm{E}\left(\frac{\partial \mathbf{K}_{\mathrm{b}_{\mathrm{i}} \mathrm{b}_{\mathrm{j}}}}{\mathbf{h}}\right) \mathrm{E}(\mathbf{u})+\mathrm{E}\left(\mathbf{K}_{\mathrm{b}_{\mathrm{i}}}\right) \mathrm{E}\left(\mathbf{u}_{\mathrm{b}_{\mathrm{i}}}\right)\right.\right. \\
+\left(\frac{\partial \mathbf{K}_{\mathrm{b}_{\mathrm{i}}}}{\partial \mathbf{h}}\right) \mathrm{E}\left(\mathbf{u}_{\mathrm{b}_{\mathrm{i}}}\right)+\frac{1}{2} \mathrm{E}\left(\frac{\partial \mathbf{K}}{\partial \mathbf{h}}\right) \mathrm{E}\left(\mathbf{u}_{\left.\left.\left.\mathrm{b}_{\mathrm{i}} \mathrm{b}_{\mathrm{j}}\right)\right]\right\}}\right. \\
\times \operatorname{Cov}\left(\mathrm{b}_{\mathrm{i}}, \mathrm{b}_{\mathrm{j}}\right)
\end{aligned}
$$




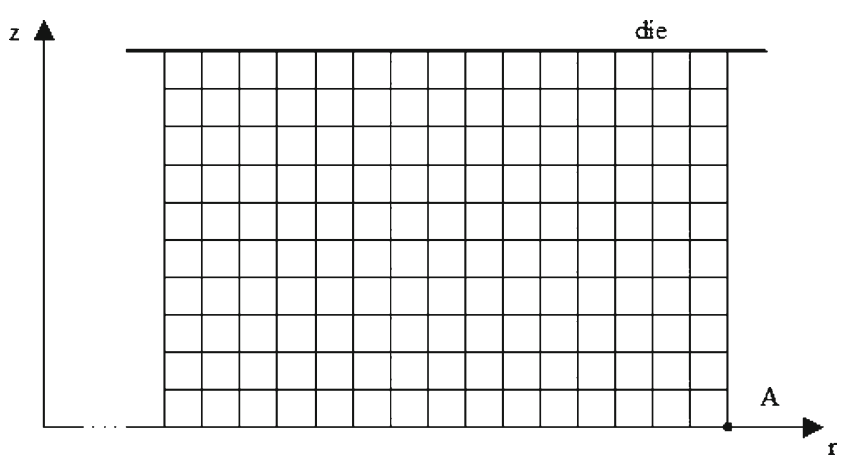

Fig. 1 Finite element mesh used for compression of rigid-poroplastic ring

$$
\hat{\mathbf{u}}_{2}=\frac{1}{2} \sum_{i, j=1}^{\mathrm{q}} \mathrm{E}\left(\frac{\partial \mathbf{u}_{\mathrm{b}_{\mathrm{i}}} \mathrm{b}_{\mathrm{j}}}{\mathbf{h}}\right) \operatorname{Cov}\left(\mathrm{b}_{\mathrm{i}}, \mathrm{b}_{\mathrm{j}}\right)
$$

\section{Numerical examples}

Modern metallurgical technology requires materials with improved characteristics as wear and corrosion resistance as well as specific strength properties. In this context powder metallurgy has much to offer because powder metallurgical processing produces materials of extremely fine and uniform microstructure and enables the formulation of materials composed from different constituents yielding unique property combinations. We can change and optimize material properties of powder materials by mixing the different powders of quite different properties, and then obtain the materials of specific properties.

We consider the simulation of compression of rigidporoplastic ring with random material properties. In metal forming analysis it is important to choose the proper proportions of diameters to the height of the specimen. A standard ring haring an outside diameter of $60 \mathrm{~mm}$, inner diameter $30 \mathrm{~mm}$ and height $20 \mathrm{~mm}$ is considered (i.e. outside diameter/inner diameter/height is equal to $6: 3: 2$ ). Because of symmetry of the problem we use the initial mesh system as shown in Fig. 1. Assume the flow curve for a rigid-poroplastic material model with power hardening as

$\bar{\sigma}=\mathrm{Y}_{\mathrm{o}}[1+(\gamma \bar{\varepsilon})]^{\mathrm{n}}$

where $\mathrm{Y}_{o}, \gamma$ and $\mathrm{n}$ are material constants. In our analysis we assume three kinds of randomizes in material properties. First we assume that $\mathrm{n}$ is random parameter, and next that $\gamma$ and $\mathrm{Y}_{o}$ are random.

Let the loading function $\mathrm{F}$ be in the form given by the expression (2). The parameter A appearing in loading function is assumed to be a function of relative density $\tilde{\rho}$

$A=\tilde{\rho}^{2}+2$

The apparent yield stress of porous materials $Y_{\tilde{\rho}}$ appearing in expression (2) is assumed as

$Y_{\tilde{\rho}}^{2}=\mu(\tilde{\rho}) Y_{b}^{2}$

where

$\mu=2 \tilde{\rho}^{2}-1$

The following deterministic characteristics of the process were assumed: friction factor $\mathrm{m}=1$, initial relative density 0.800 and $\mathrm{Y}_{\mathrm{O}}=10 \mathrm{MN} / \mathrm{m}^{2}$. In the process of compression the reduction in height $20 \%, 30 \%$ and $40 \%$ is performed.
Fig. 2 Distribution of relative densities for deterministic simulation of compression of rigid-poroplastic ring at $20 \%$ and $40 \%$ reductions in height for initial relative density of the specimen 0.800 and friction factor $\mathrm{m}=1$

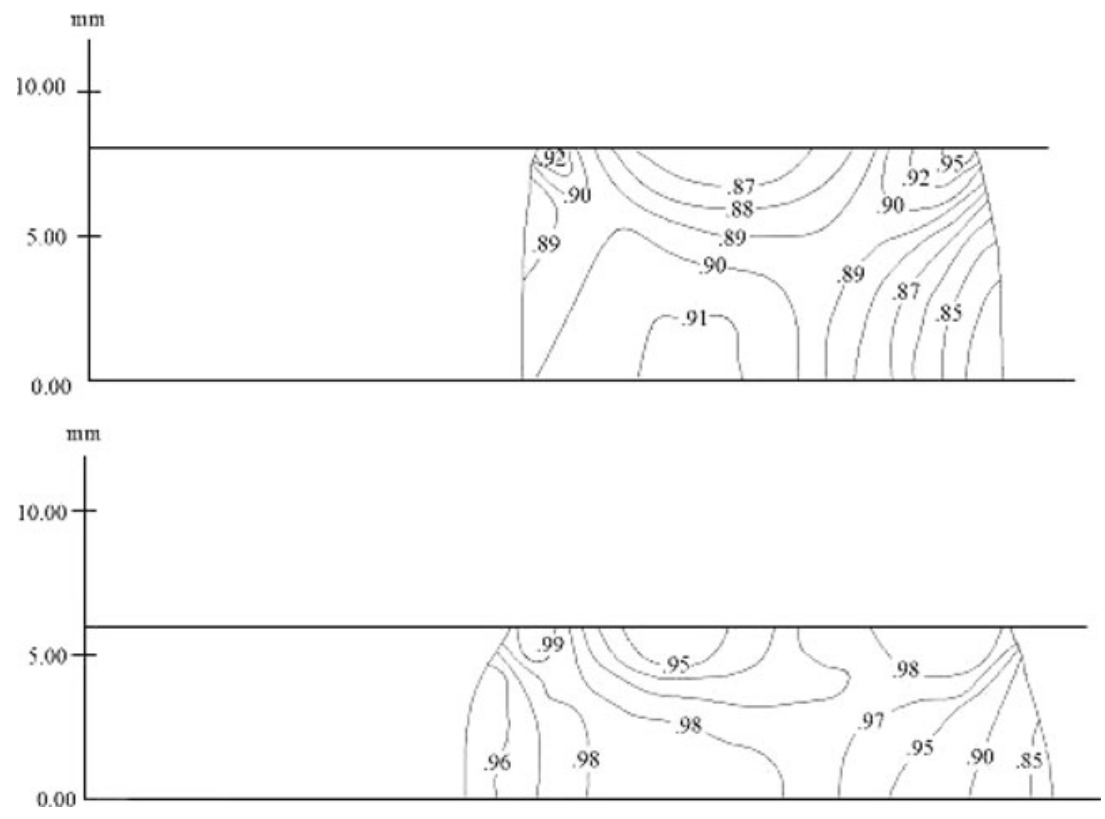




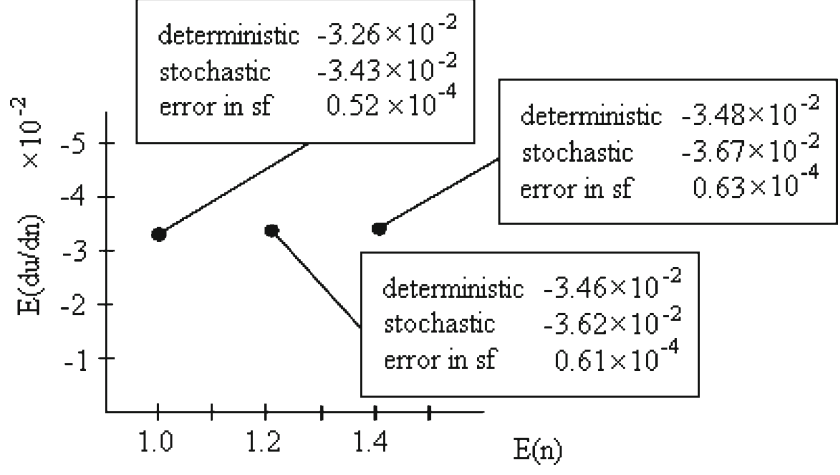

Fig. 3 Stochastic and deterministic sensitivities du/dn versus $n$ in $r-$ direction of the middle-outer point of the specimen for reduction $20 \%$ in height and errors of sensitivities in stochastic formulation (error in sf)

In order to illustrate the modelling deterministic process the Fig. 2 has been attached where the predicted relative density distributions in simple compression test are presented at $20 \%$ and $40 \%$ reductions in height for chosen parameters $\mathrm{n}=1$ and $\gamma=0.7$.

We can change and optimize material properties of powder materials by mixing the different powders of quite different properties, and then obtain the materials of specific properties; in particular we can modify the strain-stress curve given by (39). In our example we analyze the material parameters of powder metallurgy material such as $\mathrm{Y}_{\mathrm{o}}, \mathrm{n}$ and $\gamma$ which can be change by powder metallurgy processing. The examples presented are the most practical engineering problem where material parameters $\mathrm{Y}_{\mathrm{o}}, \mathrm{n}$ and $\gamma$ of powder metallurgy materials are considered as a random variables. The changes of these parameters in realistic powder metallurgy processing has a random character. Other random conditions of the process such as boundary conditions are not so important in powder metallurgy processing and do not differ from standard formulations used in metal forming.

Three examples concerning stochastic sensitivity are solved. In the first one the parameter $\mathrm{n}$ appearing in the flow curve (39) is considered as a random variable. The simula- tion is carried out for three expectation of values $\mathrm{n}$ : $\mathrm{E}(\mathrm{n})=$ $1.0, \mathrm{E}(\mathrm{n})=1.2$ and $\mathrm{E}(\mathrm{n})=1.4$. The random data for parameter $\mathrm{n}$ are the following:

$$
\begin{aligned}
\operatorname{Cov}\left(\mathrm{n}_{\alpha}, \mathrm{n}_{\beta}\right)= & \vartheta \exp \left(-\frac{\left|\mathrm{r}_{\alpha}-\mathrm{r}_{\beta}\right|}{\lambda}\right) \\
& \times \exp \left(-\frac{\left|\mathrm{z}_{\alpha}-\mathrm{z}_{\beta}\right|}{\lambda}\right)
\end{aligned}
$$

where $\mathrm{n}_{\mathrm{i}}=\mathrm{n}\left(\mathrm{r}_{\mathrm{i}}, \mathrm{z}_{\mathrm{i}}\right), \mathrm{r}$ and $\mathrm{z}$ are coordinates as shown in Fig. $1, \vartheta=0.01$ and correlation length $\lambda=10$.

In the second example the parameter $\gamma$ appearing in the flow curve is considered as a random variable. The following four expectation of values for $\gamma$ are assumed: $E(\gamma)=$ $0.7, \mathrm{E}(\gamma)=0.8, \mathrm{E}(\gamma)=0.9$ and $\mathrm{E}(\gamma)=1.0$. The random data for $\gamma$ are adopted as follows:

$$
\begin{aligned}
\operatorname{Cov}\left(\gamma_{\alpha}, \gamma_{\beta}\right)= & \vartheta \exp \left(-\frac{\left|\mathrm{r}_{\alpha}-\mathrm{r}_{\beta}\right|}{\lambda}\right) \\
& \times \exp \left(-\frac{\left|\mathrm{z}_{\alpha}-\mathrm{z}_{\beta}\right|}{\lambda}\right)
\end{aligned}
$$

where $\gamma_{\mathrm{i}}=\gamma\left(\mathrm{r}_{\mathrm{i}}, \mathrm{z}_{\mathrm{i}}\right), \mathrm{r}$ and $\mathrm{z}$ are coordinates as shown in Fig. $1, \vartheta=0.01$ and correlation length $\lambda=10$.

The compression test was carried out using step by step method. As to the step-by-step method we refer to (Bathe 1995) for instance. The reduction in height at each step was $1 \%$.

The results of calculated stochastic sensitivities on materials parameters $\mathrm{n}$ and $\gamma$ in outer middle point of the specimen (point $\mathbf{A}$ in Fig. 1) are given in Figs. 3 and 4. The results are obtained for time steps to assurance the required linearization of governing equations. It comes out from the sensitivity analysis for parameters $\mathrm{n}$ and $\gamma$ that these parameters have low sensitivity in the problem considered.

In the third example the parameter $\mathrm{Y}_{\mathrm{o}}$ appearing in the flow curve (39) is considered as a random variable. The simulation is carried out for three expectation of values $\mathrm{Y}_{\mathrm{O}}$ :
Fig. 4 Stochastic and deterministic sensitivities $\mathrm{du} / \mathrm{d} \gamma$ versus $\gamma$ in r-direction of the middle-outer point of the specimen for reduction $40 \%$ in height and errors of sensitivities in stochastic formulation (error in sf)

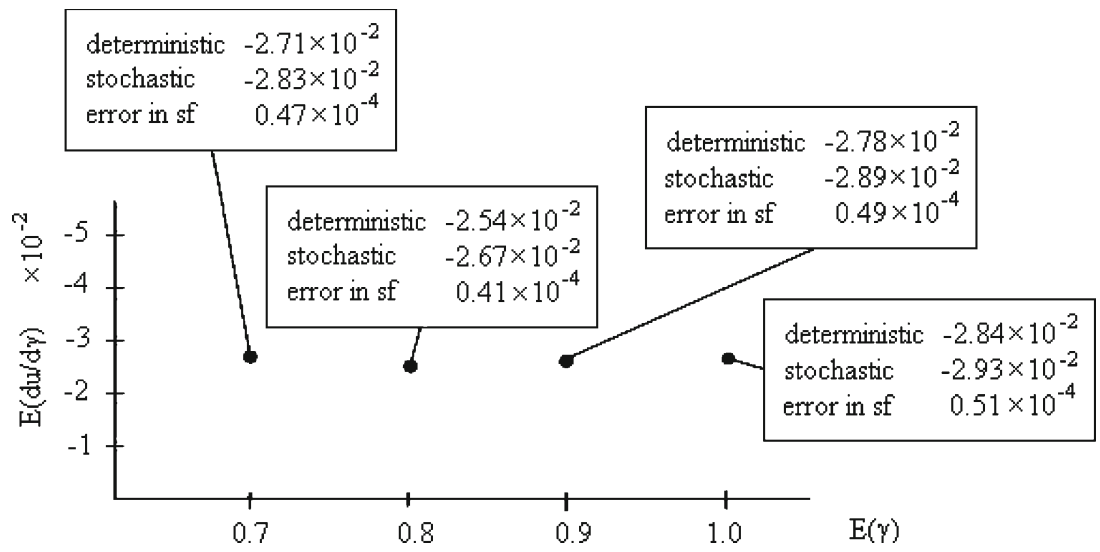


Fig. 5 Stochastic and deterministic sensitivities $\mathrm{du} / \mathrm{dY}_{\mathrm{o}}$ versus $\mathrm{Y}_{\mathrm{o}}$ in r-direction of the middle-outer point of the specimen for reduction $30 \%$ in height and errors of sensitivities in stochastic formulation (error in sf)

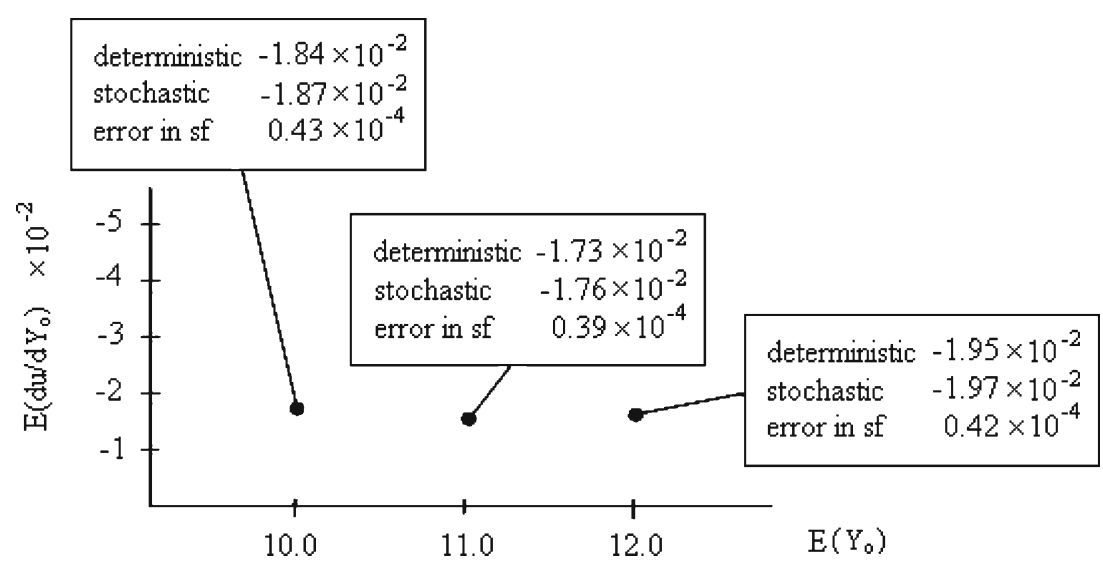

$\mathrm{E}\left(\mathrm{Y}_{\mathrm{o}}\right)=10.0, \mathrm{E}\left(\mathrm{Y}_{\mathrm{o}}\right)=11.0$ and $\mathrm{E}\left(\mathrm{Y}_{\mathrm{o}}\right)=12.0$. The following random data for $\mathrm{Y}_{\mathrm{o}}$ are adopted:

$$
\begin{aligned}
\operatorname{Cov}\left(\mathrm{Y}_{\mathrm{o} \alpha}, \mathrm{Y}_{\mathrm{o} \beta}\right)= & \vartheta \exp \left(-\frac{\left|\mathrm{r}_{\alpha}-\mathrm{r}_{\beta}\right|}{\lambda}\right) \\
& \times \exp \left(-\frac{\left|\mathrm{z}_{\alpha}-\mathrm{z}_{\beta}\right|}{\lambda}\right)
\end{aligned}
$$

where $\mathrm{Y}_{\mathrm{oi}}=\mathrm{Y}_{\mathrm{o}}\left(\mathrm{r}_{\mathrm{i}}, \mathrm{Z}_{\mathrm{i}}\right), \mathrm{r}$ and $\mathrm{z}$ are coordinates as shown in Fig. $1, \vartheta=0.01$ and correlation length $\lambda=10$.

The compression test was carried out using step by step method with reduction in height at each step $1 \%$. The results of stochastic sensitivities on materials parameter $Y_{\mathrm{o}}$ in outer middle point of the specimen (point $\mathbf{A}$ in Fig. 1 are given in Fig. 5. Similarly the results are obtained for time steps to assurance the required linearization of governing equations. It comes out from the sensitivity analysis for parameter $Y_{O}$ that this parameter has low sensitivity in the problem considered and the magnitudes of stochastic sensitivity for $\mathrm{Y}_{\mathrm{O}}$ are larger than of the deterministic sensitivity.

In order to verify the stochastic results the comparison with finite difference sensitivities in stochastic formulation has been presented. The absolute errors in these differences are shown in Figs. 3, 4 and 5 and are denoted as error in sf.

\section{Concluding remarks}

The matrix equations and general procedures for stochastic sensitivity in forging of rigid-poroplastic materials have been discussed. For this purpose the finite element method has been adopted. In the paper only parameter sensitivity is discussed. The method proposed is the useful tool for the analysis of stochastic sensitivity in forming processes. Numerical simulations were performed to illustrate of the problem undertaken. These simulations show stochastic sensitivity in the problem of ring compression of rigidporoplastic material. The derivations presented in the paper show that stochastic sensitivity of metal forming of rigidporoplastic material can be effectively carried out using stochastic finite element method. The results derived can be used for the subsequent quantitative stochastic design and stochastic optimization.

Open Access This article is distributed under the terms of the Creative Commons Attribution Noncommercial License which permits any noncommercial use, distribution, and reproduction in any medium, provided the original author(s) and source are credited.

\section{References}

Bathe KJ (1995) Finite element procedures. Prentice Hall

Grzywinski M, Sluzalec A (2002) Stochastic equations of rigidthermo-viscoplasticity in metal forming process. Int J Eng Sci 40:367-383

Haug EJ, Arora JS (1979) Applied optimal design. Wiley, New York

Haug EJ, Choi KK, Komkov V (1986) Design sensitivity analysis of structural systems. Series in Math. Sci. Eng. Academic, New York

Kleiber M, Hien TD, Antunez H, Kowalczyk P (1995) Parameter sensitivity of elastoplastic response. Eng Comput 12:263-280

Kuhn H (1978) Powder metallurgy processing. Academic, New York

Liu K, Belytschko T, Mani A (1986a) Probabilistic finite elements for nonlinear structural dynamics. Comput Methods Appl Mech Eng $56: 61-81$

Liu K, Belytschko T, Mani A (1986b) Random field finite elements. Int J Numer Methods Eng 23:1831-1845

Pokorska I (2007) Modeling of powder metallurgy processes. Adv Powder Technol 18(5):503-539

Pokorska I (2008a) Experimental identification of yield stress for sintered materials. Powder Metall Met Ceram 47:7-8 (462):25-31

Pokorska I (2008b) Visco-plastic properties of pure iron, copper and aluminum powders. Powder Metall 51(4):361-367

Pokorska I (2008c) Re-identification problems in forming of rigid-visco-poroplastic materials. Int J Numer Methods Eng 73(8):1077-1093

Pokorska I (2008d) A sensitivity analysis of powder forging processes. Struct Multidiscipl Optim 37(1):77-89

Repalle J, Grandhi R, Choi J (2007) Continuum-based shape sensitivity analysis for steady-state metal forming processes. Int J Form Process 10/2:195-218

Sluzalec A (2000) Simulation of stochastic metal forming process for rigid-viscoplastic material. Int J Mech Sci 42:1935-1946

Sluzalec A (2004) Theory of metal forming plasticity, classical and advanced topics. Springer 